\title{
Cryptococcal Meningoencephalitis: Time For Action
}

Stott KE ${ }^{1,2}$, Loyse $\mathrm{A}^{3}$, Jarvis J ${ }^{4}$, Alufandika $\mathrm{M}^{2}$, Harrison TS ${ }^{3}$, Mwandumba $\mathrm{HC}^{2,6}$, Day JN 7,8, Lalloo DG ${ }^{6}$, Bicanic $\mathrm{T}^{3}$, Perfect ${ }^{9}$, , Hope $\mathrm{W}^{1}$

${ }^{1}$ Antimicrobial Pharmacodynamics and Therapeutics, Institute of Translational Medicine, University of Liverpool, Liverpool Health Partners, Liverpool, UK

${ }^{2}$ Malawi-Liverpool-Wellcome Trust Clinical Research Programme, University of Malawi College of Medicine, Blantyre, Malawi

${ }^{3}$ Institute of Infection and Immunity, St George's University and Hospital, London, UK

${ }^{4}$ Botswana Harvard AIDS Institute Partnership, Gaborone, Botswana

${ }^{5}$ Department of Clinical Research, Faculty of Infectious and Tropical Diseases, London School of Hygiene and Tropical Medicine, London, UK

${ }^{6}$ Liverpool School of Tropical Medicine, Liverpool, UK

${ }^{7}$ Oxford University Clinical Research Unit, Ho Chi Minh City, Viet Nam

${ }^{8}$ Centre for Tropical Medicine and Global Health, Nuffield Department of Medicine, University of Oxford, UK

${ }^{9}$ Division of Infectious Diseases and International Health, Duke University School of Medicine, Durham, NC, USA

\section{Corresponding author:}

Katharine E Stott

Antimicrobial Pharmacodynamics and Therapeutics Institute of Translational Medicine University of Liverpool UK katstott@liverpool.ac.uk 
Word Count: 4506

\section{Key Words}

Cryptococcus

Cryptococcal meningitis

Neglected diseases

Low- and middle-income countries

People living with HIV

Antifungal therapeutics

Advanced HIV disease 


\section{Summary}

Cryptococcal meningoencephalitis was first described over a century ago. It is preventable and treatable yet continues to be associated with excessive morbidity and mortality. The largest burden of disease resides with people living with HIV (PLHIV) in low- and middleincome countries (LMICs). In this group, mortality with the best antifungal induction regimen (seven days of amphotericin B deoxycholate $(1.0 \mathrm{mg} / \mathrm{kg} / \mathrm{day})$ and flucytosine (100 $\mathrm{mg} / \mathrm{kg} /$ day)) in a clinical trial setting is $24 \%$ at 10 weeks. The world is now at an inflection point in terms of recognition, research and action to address the burden of morbidity and mortality from cryptococcal meningoencephalitis. However, the scope of programs needs to increase, with particular attention to translational science that is specific to individual countries. This review summarises causes of excessive mortality, interventions with demonstrated survival benefit, and gaps in knowledge and practice that contribute to the ongoing high death toll from cryptococcal meningoencephalitis. 


\section{Cryptococcal Meningoencephalitis}

Cryptococcosis is an invasive fungal disease caused by the ubiquitous basidiomycete yeasts Cryptococcus neoformans and Cryptococcus gattii. ${ }^{1}$ C. neoformans is responsible for $95 \%$ of human cryptococcal disease, ${ }^{2}$ although $C$. gattii is increasingly recognised as a pathogen of global relevance. ${ }^{3,4}$ Cryptococcosis encompasses a spectrum that ranges from latent infection, through subclinical disseminated disease, to fulminant meningoencephalitis. The latter occurs commonly in the setting of advanced immunosuppression and is uniformly fatal without antifungal therapy. ${ }^{5}$

Cryptococcal meningoencephalitis is frequently associated with advanced HIV disease (AHD), ${ }^{6}$ in which context it causes an estimated 223,000 incident cases per year and 180,000 deaths. Cryptococcal meningoencephalitis also occurs in solid-organ transplant recipients, patients with malignancy and other immunosuppressive conditions, as well as in apparently immunocompetent hosts. ${ }^{7}$ Clinical manifestations include headache, seizures, cranial nerve abnormalities and altered mentation, which often progresses to coma and death. In survivors, $69 \%$ of PLHIV and 73\% of non-HIV patients suffer cognitive and/or physical impairment 12 months after diagnosis. ${ }^{8,9}$ More than a third of patients report difficulty or inability to work 6 months after diagnosis. ${ }^{8}$ A number of recent scientific and policy advances have contributed to improved identification and management of patients with cryptococcal meningoencephalitis worldwide. However, much remains to be done.

\section{Efforts to control the HIV/AIDS epidemic have not reduced the global burden of cryptococcal meningoencephalitis}

Surveillance data from Botswana ${ }^{10}$ and South Africa ${ }^{11,12}$ suggest that despite excellent population antiretroviral therapy (ART) coverage, the incidence of cryptococcal 
meningoencephalitis remains high. A reduction in the number of patients presenting to HIV services de novo with low CD4+ cell count has been offset by an increase in individuals presenting with advanced immunosuppression having defaulted or failed ART. The characteristics of patients presenting with cryptococcal meningoencephalitis has shifted from primarily ART-naïve, to $>50 \%$ being ART-experienced ${ }^{12-14}$. Therefore, while regions of high HIV prevalence bear a high burden of mortality from cryptococcal meningoencephalitis, expanded access to widespread HIV treatment appears insufficient to substantially reduce cryptococcal deaths (Figure 1).

To markedly reduce mortality from cryptococcal meningoencephalitis, HIV care cascades must be strengthened to sustain virological suppression at population level. In parallel, there must be focus on early diagnosis of cryptococcal meningoencephalitis. Development of novel therapeutic strategies is urgently required. Interventions with proven survival benefit must be implemented within routine clinical care, which in many settings requires better funding, staffing, training and access to commodities. More broadly, the social and health system challenges that contribute to mortality must be addressed.

\section{Clinicopathological Correlates of Death}

Early Detection and Management of Cryptococcal Infection Reduces Mortality

The development of a simple, cheap and accurate point-of-care lateral flow assay (LFA) for CrAg has been a significant advance for detection of pre-symptomatic cryptococcal infection. CrAg is detectable in blood 6 to 7 months before the onset of symptoms and independently predicts meningitis and death..$^{29,30}$ The REMSTART trial showed that in conjunction with adherence support, $\mathrm{CrAg}$-based screening and antifungal treatment can reduce mortality in people with AHD initiating ART by $28 \%$ compared to standard clinic-based 
care alone $(p=0.004) .{ }^{31}$ Decision-tree modelling has predicted that universal $\mathrm{CrAg}$ screening and pre-emptive fluconazole therapy for PLHIV with CD4 $<100$ cells/ $\mu$ l would avert 25 disability-adjusted life years (DALYs) per 100 participants, at a cost of US\$6.14 per DALY. ${ }^{32}$ The comparable figure for cost per DALY averted for PLHIV on ART prescribed 9 months of isoniazid tuberculosis preventive therapy (IPT) is US\$266..$^{33}$ Both calculations are based on PLHIV in Ugandan HIV clinics and on 2016/ 2017 US\$. ${ }^{32,33}$ A CrAg-based 'screen-and-treat' strategy is recommended by the World Health Organisation (WHO) for PLHIV with CD4+ counts $<100$ cells $/ \mathrm{mm}^{3}$ (and should be considered for CD4+ $<200$ cells $/ \mathrm{mm}^{3}$ ). ${ }^{34}$ Although implementation and scale up of screen-and-treat programs has been slow, they are now operational in more than 25 countries worldwide. Nevertheless, the lack of universal coverage remains a significant obstacle to reducing the incidence of cryptococcal meningoencephalitis. ${ }^{35}$

To capitalise on the potential survival benefit presented by screen-and-treat programs, there are three key areas in need of further research. First, innovative therapeutic strategies are urgently required for CrAg-positive individuals identified through screening. Between 13 and $25 \%$ of asymptomatic CrAg-positive patients fail pre-emptive fluconazole therapy, proceeding to clinical cryptococcal meningoencephalitis or death by 6 months. ${ }^{31,36,37}$ The ongoing ACACIA trial (NCT03945448) compares a single dose of liposomal amphotericin B (LAmB; $10 \mathrm{mg} / \mathrm{kg}$ ) plus fluconazole, to fluconazole alone for asymptomatic cryptococcal antigenaemia. An oral combination of flucytosine and fluconazole may be an alternative and this will be investigated in the EFFECT trial (personal communication, JNJ and TSH). Second, implementation research is needed to identify local barriers to implementation of $\mathrm{CrAg}$ screening, obstacles to treatment adherence and strategies to improve loss to follow-up. Third, the role of semiquantitative CrAg assays in stratifying patients requiring urgent 
investigation for CNS disease or more intensive pre-emptive therapy requires further investigation..$^{34,38}$

\section{Clinical Signs Provide Clues to Pathology}

Once CNS disease is established, a high fungal burden in cerebrospinal fluid (CSF) and baseline alterations in mental status are two independent predictors of mortality from cryptococcal meningoencephalitis. ${ }^{39}$ While data directly linking either seizures at baseline or increased intracranial pressure (ICP) at baseline with mortality are inconsistent, these clinical features are themselves associated with higher CSF fungal burden and altered mental status. ${ }^{39-41} \mathrm{~A}$ greater fungal burden in CSF is likely to reflect higher cryptococcal density in the brain parenchyma and central nervous system (CNS) as a whole. The term meningoencephalitis is more accurate than meningitis because it acknowledges the propensity for involvement of brain parenchyma and ventricles as well as the meninges. ${ }^{42,43}$ Large cryptococcomas are characteristic of cryptococcal meningoencephalitis in $\mathrm{AHD}^{42}$ and especially infection with C. gattii. $^{44}$

\section{The Significance of Raised Intracranial Pressure}

The large burden of fungal cells in and around the brain increases CSF viscosity, obstructs CSF flow and impedes CSF reabsorption. ${ }^{45}$ Cerebral oedema results from dramatic increases in ICP, with pressures $>250 \mathrm{~mm}$ CSF in $51-56 \%$ of cases. ${ }^{46}$ Clinical manifestations include headache, cranial nerve abnormalities and reduced level of consciousness.

Raised ICP must be managed aggressively with antifungal therapy and repeated CSF drainage. Serial lumbar punctures (LPs) performed during the first 14 days of therapy mitigate the association between raised baseline opening pressure and mortality. ${ }^{47,48}$ Importantly, 
accurate recording of raised ICP requires a manometer - a simple cylinder attached to a threeway tap that fits onto the end of an LP needle. This basic equipment is almost universally unavailable in LMICs and some groups have devised innovative alternative methods of ICP measurement, including using intravenous tubing sets ${ }^{49}$ and the less accurate but more available method of counting drops of CSF flowing from a spinal needle. ${ }^{50}$ In the absence of any means of measuring ICP, removal of a pre-defined volume of CSF is a contentious strategy since large falls in pressure can be difficult to predict. $^{51}$

\section{Rapid Reduction in Fungal Load is Paramount}

The rate of decline of fungal burden with antifungal treatment is linked with the risk of death. ${ }^{39,48}$ Early fungicidal activity (EFA) (i.e. a linear regression of $\log _{10}$ colony forming units (CFU)/mL vs. time) is routinely used as a primary endpoint for Phase II clinical studies and a secondary endpoint in Phase III trials. ${ }^{14,52,53}$ A pooled analysis of individual-level CSF data from 738 subjects suggests that an EFA $<0.20 \log _{10} \mathrm{CFU} / \mathrm{mL} /$ day versus $>=0.20$ $\log _{10} \mathrm{CFU} / \mathrm{mL} /$ day is associated with a hazard ratio for 18 -week mortality of $1.60(95 \% \mathrm{Cl}, 1.25$ - 2.04, $p=0.002) .{ }^{54}$ Similarly, in a combined analysis of 501 ART-naïve patients, EFA values > $0.2 \log _{10} \mathrm{CFU} / \mathrm{mL} /$ day were associated with the greatest probability of survival. ${ }^{55}$

\section{People die of cryptococcal meningoencephalitis due to suboptimal antifungal therapy}

Just three antifungal agents (amphotericin B deoxycholate (DAmB), flucytosine and fluconazole) are widely available for the treatment of HIV-associated cryptococcal meningoencephalitis in LMICs. The most effective regimen in terms of fungicidal activity and mortality is a combination of DAmB and flucytosine, with the combination of fluconazole and 
flucytosine an alternative. ${ }^{14,53,56}$ The combination of DAmB and fluconazole is less

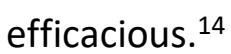

At present, most healthcare systems worldwide that manage patients with cryptococcal meningoencephalitis do not have the resources to deliver effective antifungal therapy, which is predicated on a rapid and sustained reduction in fungal load within the CNS. An improved understanding of the pharmacokinetics and pharmacodynamics of polyenes has enabled a number of innovative induction regimens. The ACTA trial demonstrated the noninferiority of one week of DAmB (1 mg/kg/day) plus flucytosine (100 mg/kg/day) followed by 7 days of fluconazole ( $1200 \mathrm{mg} /$ day) versus regimens based on two weeks of DAmB, in terms of mortality at ten weeks ${ }^{14}$ and one year. ${ }^{57}$ The ongoing AMBITION trial tests this approach further by exploiting the relative safety of $L A m B$, testing induction therapy with a single high dose of LAmB (10 mg/kg) plus 14 days of fluconazole (1200 mg/day) and flucytosine (100 $\mathrm{mg} / \mathrm{kg} /$ day). ${ }^{58}$

Flucytosine is an essential component of effective induction regimens for cryptococcal meningoencephalitis. Combined with DAmB, flucytosine produces more rapid fungicidal activity than fluconazole and enables abbreviation of the course of amphotericin B, thereby minimising toxicity. ${ }^{14,53}$ The intrinsic superiority of flucytosine over fluconazole in DAmBbased regimens is probably multifactorial and related to drug penetration into the $\mathrm{CNS}^{59} \mathrm{a}$ long post antifungal effect $^{60}$ and pharmacodynamic synergism between polyenes and flucytosine. ${ }^{61}$

Despite clear evidence of the superiority of regimens containing flucytosine and/or $\mathrm{DAmB}$, many patients with cryptococcal meningoencephalitis are treated with fluconazole monotherapy. Mortality rates are $40-70 \%$ with this approach. ${ }^{62-65}$ Recent clinical data provide evidence of the acquisition of fluconazole-resistant cryptococcal subpopulations from the 
environment, and their expansion on fluconazole monotherapy $(800-1200 \mathrm{mg} / \mathrm{kg} / \mathrm{day}){ }^{66}$ Combination therapy with fluconazole $(1200 \mathrm{mg} / \mathrm{kg} / \mathrm{day})$ and flucytosine $(100 \mathrm{mg} / \mathrm{kg} / \mathrm{day})$ kills these resistant subpopulations within 14 days. ${ }^{66}$ Even among patients infected with wild type strains of Cryptococcus spp., approximately half are predicted to fail monotherapy with fluconazole ( $1200 \mathrm{mg} /$ day) because they will not generate sufficient drug exposure to prevent the emergence of resistant clones. ${ }^{67}$

There are multiple reasons neither flucytosine nor DAmB are routinely administered in LMICs. First, there is lack of access to both drugs. ${ }^{68}$ Flucytosine is unregistered in the vast majority of LMICs and throughout Africa. ${ }^{69,70}$ The price of flucytosine has historically been prohibitive due to manufacturer pricing monopoly ${ }^{71}$ and a perception that profit margins from LMICs do not justify the resources required to scale up manufacturing. ${ }^{69}$ In turn, this has contributed to a lack of demand for flucytosine from practitioners who are unfamiliar with the drug. ${ }^{69,70}$ However, there is recent cause for optimism. In the AMBITION trial, flucytosine is being procured for approximately US\$180 for a 2 -week course. ${ }^{72}$ At this price, the combination of flucytosine and fluconazole is cost-effective in sub-Saharan Africa compared with fluconazole monotherapy when hospital care costs and mortality are also considered (incremental cost-effectiveness ratio (ICER) US\$65 per life-year saved). ${ }^{73}$ Furthermore, the global pharmaceutical company Mylan has received WHO prequalification for flucytosine, which will facilitate accelerated registration in $\mathrm{LMICs}^{74}$ and Strides, a generic manufacturer, has received US Food and Drug Administration (FDA) approval for the drug. ${ }^{75}$ UNITAID have announced a programme to support use of flucytosine and LAmB in 7 African countries. ${ }^{76}$ In South Africa, flucytosine is available for routine use in the Western Cape and at a number of tertiary centres, with early indications of a subsequent fall in in-hospital mortality. ${ }^{69}$ 
For the most effective regimen of 1 week of DAmB plus flucytosine for induction therapy, ${ }^{14}$ the ICER per life-year saved in sub-Saharan Africa is US\$208. ${ }^{77}$ While DAmB is frequently licensed for use in $\mathrm{LMICs}^{68}$ it remains unaffordable or unavailable in much of Africa. Training for safe DAmB administration is scarce and funding and procurement uncoordinated. ${ }^{70}$ Access is somewhat better in Asia, where regional generic manufacturers can produce DAmB. ${ }^{34}$ However, there are indications of progress. Amphotericin B formulations, flucytosine and fluconazole are now included in the WHO Model List of Essential Medicines. ${ }^{78}$ The availability of LAmB should increase in 116 LMICs in response to an access initiative from Gilead Sciences. ${ }^{79}$ The ARV Procurement Working Group (APWG), whose members include CHAI, PEPFAR, The Global Fund and 3 offices of the United Nations, recently expanded its scope to include $\mathrm{LAmB}, \mathrm{DAmB}$ and flucytosine in its list of monitored products. ${ }^{80}$

The second barrier to effective antifungal therapy in LMICs is the inability to monitor and manage life-threatening adverse events. This is especially the case for DAmB, which can cause dose-related nephrotoxicity, electrolyte derangements leading to cardiotoxicity, and direct suppression of erythropoiesis resulting in severe anaemia. ${ }^{81,82}$ Pharmacokinetic data suggest that dosages of DAmB that approach $1 \mathrm{mg} / \mathrm{kg} /$ day cause enough toxicity to offset mortality gains made in terms of CSF sterilisation. ${ }^{83}$ While DAmB dosages approaching 1.0 $\mathrm{mg} / \mathrm{kg} /$ day have not been directly compared in monotherapy in a clinical trial, $0.7 \mathrm{mg} / \mathrm{kg} / \mathrm{day}$ and $1 \mathrm{mg} / \mathrm{kg} /$ day have been compared in combination with flucytosine $(100 \mathrm{mg} / \mathrm{kg} /$ day $) .{ }^{84}$ The $1 \mathrm{mg} / \mathrm{kg} /$ day dosage was associated with higher EFA but not with a reduction in mortality. ${ }^{84}$ Abbreviated amphotericin B-based regimens are hoped to improve the balance between fungicidal efficacy and tolerability. ${ }^{14,58}$

The option of an all-oral regimen of flucytosine and fluconazole mitigates some of the risks of parenteral drug administration. The safety profile of flucytosine compares favourably 
$\mathrm{DAmB}$, although it can cause dose-dependent bone marrow suppression and hepatotoxicity. ${ }^{85}$ Fluconazole undergoes extensive metabolism in the liver and can (rarely) cause reversible hepatocellular toxicity.

Thirdly, the prospect of effective antifungal therapy is limited by polypharmacy, most frequently with ART and anti-tuberculosis medications. Drug interactions are common. Rifampicin reduces the area under the concentration-time curve of fluconazole by $22 \%,{ }^{86}$ limiting the likelihood of fluconazole pharmacokinetic target attainment. The potential for additive toxicity underscores the obligation to monitor renal and hepatic function, possibly for months - for example with IPT and long term fluconazole. ${ }^{87}$ The pill burden for patients taking prolonged therapy for polymicrobial infection is onerous and suboptimal adherence is common. $^{31}$

\section{Patients Die Because of an Inability to Predict and Manage Immunological Dysregulation}

The role of inflammation in pathogenesis is complex

Survival from cryptococcal meningoencephalitis depends on a balanced inflammatory response - sufficient to clear the fungus, but not so much that it induces collateral damage to the host (see the damage-response framework of microbial pathogenesis). ${ }^{88,89} \mathrm{~A}$ parabolic relationship exists such that host damage is maximal in response to both the weakest and the strongest immune responses. ${ }^{89}$ The inability to predict where an individual is located along the damage-response framework parabola renders the design of interventions to control the host response fraught with uncertainty. ${ }^{88,89}$

The potential of immunological adjuncts to standard antifungal therapy has not yet been realised 
In patients with a first episode of HIV-associated cryptococcal meningoencephalitis, low baseline levels of pro-inflammatory cytokines (i.e. interferon (IFN)- $\gamma$, tumour necrosis factor (TNF)- $\alpha$ and interleukins 2, 6, 8 and 17) are associated with increased mortality. ${ }^{39,90,91}$ Conversely, an early pro-inflammatory response and classical macrophage activation imparts an EFA and mortality benefit. ${ }^{90-93}$ In HIV-negative patients, there may be a relatively strong cellular immune response in the CNS with abundant pro-inflammatory cytokines, but dysfunctional phagocytosis. ${ }^{94}$

Interventions designed to augment the host response are not in routine use. Two clinical trials have demonstrated that administration of IFN- $\gamma$ in combination with amphotericin B promotes inflammation, increases fungal clearance from CSF and produces a trend towards improved survival in HIV-associated cryptococcal meningoencephalitis. ${ }^{93,95}$ However, this has not been tested in Phase III clinical trials. Further work is needed to select those patients most likely to benefit - likely those with minimal endogenous IFN- $\gamma$ responses. ${ }^{96}$ The use of monoclonal antibodies directed against cryptococcal capsular polysaccharide presents another promising approach. One such antibody, 18B7, was well tolerated up to doses of $1 \mathrm{mg} / \mathrm{kg}$ in a Phase I clinical trial ${ }^{97}$ although no efficacy data currently exist.

Concerns related to an overly exuberant immune response have prompted the use of anti-inflammatory agents. There are case reports of corticosteroids reducing raised ICP and/or improving neurological sequelae in non-HIV cryptococcal meningoencephalitis ${ }^{98-100}$. In contrast, the use of dexamethasone is detrimental as an adjunct to antifungal therapy in PLHIV. While it does reduce ICP in this population, it is associated with rapid early declines in TNF- $\alpha$ in CSF, ${ }^{101}$ slower clearance of Cryptococcus spp. from CSF, increased morbidity and probably excess mortality. ${ }^{52}$ 
IRIS is a persistent problem

Cryptococcal IRIS is an important cause of death. IRIS occurs in $10-20 \%$ of cryptococcal meningoencephalitis patients during immunological restoration on $\mathrm{ART}^{102-104}$ and in $5-12 \%$ of solid-organ transplant recipients. ${ }^{105}$ Risk factors in the non-HIV population include rapid reduction in immunosuppressive therapy - in particular, discontinuation of calcineurin inhibitors - and resolution of immunosuppressive disorders. ${ }^{105-107}$ In apparently immunocompetent individuals, a post-infectious inflammatory response syndrome (PIIRS) has been described, characterised by non-recovery of mental status despite sterile CSF. ${ }^{108}$

Most of the description of cryptococcal IRIS derives from HIV-associated disease. Prior to ART initiation, in patients who go on to develop IRIS, there is a paucity of inflammatory cytokines in the CNS. ${ }^{109-111}$ During immunological reconstitution, there is CNS recruitment of monocytes and T cells. ${ }^{112,113}$ However, these immunological effectors fail to completely clear the inciting antigen, ${ }^{103,110}$ leading to persistently increased levels of proinflammatory biomarkers including C-reactive protein and D-dimer. ${ }^{103,114}$ The ensuing inflammation mimics uncontrolled fungal infection with neurological signs and symptoms and raised ICP. Early ART initiation is associated with CNS cellular infiltrate, macrophage/microglial activation and increased mortality, compared with late ART initiation (1-2 weeks versus 4-6 weeks after diagnosis of cryptococcal meningoencephalitis). ${ }^{115}$ ART initiation should be deferred in cryptococcal meningoencephalitis patients if there is any risk of rapid CNS immune reconstitution based on their ART history. ${ }^{116}$ In solid-organ transplant recipients, reduction of immunosuppression is thought to promote a switch from a medically-induced Th2 dominant immunophenotype to a Th1 proinflammatory response, triggering a clinical picture 
comparable to that seen in PLHIV. ${ }^{114}$ In apparently immunocompetent patients with PIIRS there is T-cell inflammation and axonal damage but an intact IFN- $\gamma$ response. ${ }^{108}$

Treatment of IRIS remains unsatisfactory. Uncertainty about the possibility of an incompletely treated fungal infection ( $\mathrm{CrAg}$ can remain positive for years after successful treatment, and cryptococcal culture can take 14 days) often promotes long courses of induction antifungal therapy. The only agents with which there is experience for treatment of IRIS are corticosteroids, ${ }^{106,117}$ which are at best imprecise agents for rebalancing immune function. Large prospective studies involving longitudinal clinical, microbiological and immunophenotypic characterisation of subjects are required to define immune pathways amenable to safe and predictable intervention. ${ }^{118}$

\section{A complex medical and social context}

Cryptococcal meningoencephalitis is a manifestation of a severely impaired host

Advanced stages of HIV are associated with a range of debilitating and interrelated conditions including chronic diarrhoea, oesophageal candidiasis, malnutrition, disseminated mycobacterial and viral infections, recurrent sepsis, pneumonias and non-cryptococcal mycoses. ${ }^{119,120}$ At autopsy, patients with confirmed cryptococcal infection display evidence of multiple concomitant life-threatening conditions, such that the immediate cause of death is difficult to distinguish. ${ }^{37,120}$ Of 514 patients with cryptococcal meningoencephalitis in Cape Town, 10 (1.9\%) had microbiologically-confirmed dual CNS infection with tuberculosis, syphilis or bacterial meningitis. ${ }^{121}$

Cryptococcal meningoencephalitis occurs where society is stretched 
Delays to diagnosis are common in settings where resources are limited. Caring and family responsibilities, logistical challenges related to travel and opportunity costs impede early presentation to health services. Psychosocial factors are often-overlooked but potentially important contributors to late presentation. ${ }^{122}$ For patients who are able to reach a healthcare facility, a CSF India Ink preparation is positive in $70-90 \%$ of cases, ${ }^{39}$ but this depends on diagnostic laboratory facilities and expertise. In contrast, the sensitivity and specificity of the CrAg LFA in serum are up to $100 \%$ and $99.5 \%$, respectively, and in CSF $99.3 \%$ and $99.1 \%$, respectively. ${ }^{123,124}$ Thus, for diagnosis as well as pre-emptive screening, the availability of this assay is essential to improve outcomes from cryptococcal meningoencephalitis.

Mortality from cryptococcal meningoencephalitis is a symptom of under resourced healthcare systems

High quality supportive care is difficult to provide in settings where nursing staff are scarce. For comparison, per 10,000 population, there are 81.72 and 28.12 nursing staff and doctors, respectively, in the UK, 13.08 and 9.05 in South Africa and 4.39 and 0.36 in Malawi. ${ }^{125}$ Patients with cryptococcal meningoencephalitis are medically complex and often have reduced conscious level. Optimal care requires administration of intravenous therapy, frequent neurological observations, serial LPs and prevention of clinical complications. Concomitant opportunistic infections must be screened for and managed.

In 2017, the WHO recommended a package of care for patients with AHD (CD4 cell count $<200$ cells $/ \mathrm{mm}^{3}$ or WHO stage 3 or 4 event). ${ }^{126}$ The package includes CrAg screening, tuberculosis screening plus IPT, co-trimoxazole prophylaxis, guidelines on ART initiation and tailored adherence counselling. In 2019, UNITAID invested US\$ 20 million in measures 
implemented by Clinton Health Access Initiative (CHAI) intended to widen access to these packages through partnership with civil society, academia, governments, non-governmental organisations and other global health partners. ${ }^{76}$ Médecins Sans Frontières (MSF) and the Elizabeth Glaser Paediatric AIDS Foundation are among those organisations with AHD care package programs. ${ }^{127}$ These initiatives are being rolled out in 7 LMICs this year. However, the task is not trivial. Implementation must be supported by clinical and laboratory facilities, training, supervision, clinical escalation protocols, mobile outreach and follow up capacity. Evaluation of implementation will be central to refining models that can be scaled up by national administrations and other funding bodies. ${ }^{76}$

Thinking outside of the triangle; alternatives to amphotericin B deoxycholate, flucytosine and fluconazole

The drug pipeline for cryptococcal meningoencephalitis has historically been slow to progress. Clinical trials of repurposed drugs such as sertraline ${ }^{128}$ and tamoxifen ${ }^{129}$ as adjuncts to polyene-based therapy have been disappointing. An ideal antifungal candidate for cryptococcal meningoencephalitis would exhibit at least equal potency to amphotericin B, with an improved safety profile and oral administration. Thankfully, a number of promising novel agents are in development (table 1). In addition, a project run by the Drugs for Neglected Diseases Initiative (DNDi) with European and African partners that aims to develop a modified-release formulation of flucytosine was initiated in July $2020 .{ }^{140}$ Neurapheresis is a novel technique under study designed to reduce CSF fungal burden and control ICP using extracorporeal filtration of CSF. ${ }^{141}$ This may prove to be a treatment option in well-resourced settings. 
It is key that the effort committed to these novel developments is translated into tangible clinical benefits. In 2018, cryptococcal meningoencephalitis was added to the FDA list of tropical diseases that qualify for a priority review voucher. ${ }^{142}$ The WHO prequalification scheme aims to support national authorities through quality assurance. Crucially, existing and novel drugs for cryptococcal meningoencephalitis must be affordable to the countries that bear the burden of cryptococcal meningoencephalitis to be effective in a real-world sense.

\section{Challenges and Opportunities}

The burden of mortality from cryptococcal meningoencephalitis is huge. While at an individual patient level, the reasons for death are undeniably part of a larger picture of advanced immunosuppression, there are widespread systematic failings that contribute to excessive mortality. These include health system challenges, failures in the development and delivery of therapeutics and a lack of implementation capacity commensurate with the burden of suffering and mortality from this disease (Figure 2). Best treatment practices remain aspirational for many countries. Interventions with proven mortality benefit such as repeated therapeutic LPs and administration of amphotericin B and flucytosine are either unfeasible or unavailable in LMICs. Even in middle- and high-income countries, mortality rates of $20-40 \%$ persist. $^{6}$ Contrary to widespread assumption, funding for cryptococcal meningoencephalitis does not fall within the remit of HIV funding, despite being the second most frequent cause of HIV-related deaths after tuberculosis. ${ }^{6}$ Since it does not meet WHO criteria for recognition as a neglected tropical disease, it does not receive funding from this route either. ${ }^{143}$ In 2018, cryptococcal meningoencephalitis received just $0.2 \%$ (7.7 million US\$) of available relevant research and development funding, compared with $17 \%$ (684.6 million US\$) of funding directed towards R\&D for tuberculosis. ${ }^{144}$ 
Importantly, we are now at an inflection point in terms of recognition, funding, research and action to address the burden of morbidity and mortality from cryptococcal meningoencephalitis. Implementation of the LFA and trials of novel treatment regimens are essential developments that are specifically designed for implementation in the clinical settings of greatest need. ${ }^{14,58}$ The WHO has increased the strength of its recommendation for CrAg screening in at-risk populations. ${ }^{34}$ Examples of country-specific training in the prevention and management of cryptococcal meningoencephalitis now exist. ${ }^{145}$ The ACTA trial results were swiftly incorporated into WHO guidelines. ${ }^{34}$ Considerable advocacy efforts by the cryptoMAG consortium, MSF and others have played a large role in numerous significant policy advances. ${ }^{70,146}$ Cryptococcal meningoencephalitis has been declared a neglected disease in the G-finder report, highlighting the need for affordable, efficacious drugs suitable for resource-poor settings. ${ }^{147}$ The DREAMM trial (NCT03226379) is implementing packages of tests and treatment for HIV-related meningoencephalitis in Tanzania, Malawi and Cameroon. The APWG now lists flucytosine, LAmB and DAmB among its monitored products. ${ }^{80}$ The anti-cryptococcal drug development pipeline is more promising than it has been in a generation.

The cryptococcal research and advocacy community is small but active. The current era is characterised by innovation and momentum in terms of novel technologies and treatment strategies that are designed to be feasible in LMICs. It is imperative that this momentum is maintained and links with funders, large scale implementers and ministries of health strengthened. Specific priority targets for action are outlined in table 2 . While there is room for cautious optimism in considering the future for patients with cryptococcal meningoencephalitis, this is no time for complacency. The advances that have been made must be viewed as the start of a new era - significant needs remain unmet and until they are 
addressed, people will continue to die in the hundreds of thousands from a preventable and treatable disease. 


\section{Search strategy and selection criteria}

We searched PubMed and Google Scholar for articles published up to June 30, 2020, using the terms "cryptococcal meningitis", "cryptococcal meningoencephalitis", "HIV-associated meningitis" or "cryptococcosis", in combination with "mortality", "incidence", "prevalence", "screening", "drug*", "therapy", "treatment" or "IRIS". We reviewed these articles, and relevant articles in the references of these articles. No language restrictions were applied. We consulted experts in the field to identify additional relevant studies, advocacy groups, and policy advances.

\section{Acknowledgments}

KES is a Wellcome Trust Clinical PhD Fellow (203919/Z/16/Z). JND has received grant funding from the Wellcome Trust, the UK Medical Research Council, the UK Department for International Development, The National Institutes for Health, The British Medical Association, the Li Ka Shing Foundation and the British Infection Society. WH holds awards from the Medical Research Council, National Institute of Health Research, FDA and the European Commission. JNJ holds grant funding from the Wellcome Trust, the UK Medical Research Council, the UK Department for International Development, the Swedish International Development Agency, the National Institutes for Health, and the U.K. National Institute for Health Research (NIHR) using Official Development Assistance (ODA) funding through a Global Health Professorship (grant RP-2017-08-ST2-012). The views expressed are those of the authors and not necessarily those of the NHS, NIHR, or the Department of Health and Social Care.

\section{Contributors}

KES and WH conceived this Review. KES performed the initial literature search, wrote the first draft of the manuscript and designed and drafted the tables and figures. All authors contributed to, reviewed and approved the final draft.

\section{Declaration of interests}

KES, AL, MA, TH, HCM, DGL - Nil

TB has received research funding from Gilead sciences and speaker fees from Gilead Sciences and Pfizer. JND has received fees for scientific consulting for Viamet Pharmaceuticals. JRP has research grants and performs consultation for Astellas, Pfizer, Merck, F2G, Amplyx, Matinas, Scynexis, Appili and Minnetronix. WH holds or has recently held research grants with F2G, Astellas Pharma, Spero Therapeutics, Antabio, Allecra, Bugworks, and NAEJA-RGM. WH has received personal fees in his capacity as a consultant for F2G, Amplyx, Ausperix, Spero Therapeutics, VenatoRx, Pfizer and BLC/TAZ. 


\section{References}

1. May RC, Stone NRH, Wiesner DL, Bicanic T, Nielsen K. Cryptococcus: from environmental saprophyte to global pathogen. Nature Reviews Microbiology 2016; 14(2): 106-17.

2. Heitman J, Kozel TR, Kwon-Chung KJ, Perfect JR, Casadevall A. Cryptococcus: from human pathogen to model yeast: ASM press; 2010.

3. Galanis E, MacDougall L, Kidd S, Morshed M, Group BCCgW. Epidemiology of Cryptococcus gattii, British Columbia, Canada, 1999-2007. Emerging infectious diseases 2010; 16(2): 251.

4. Litvintseva AP, Thakur R, Reller LB, Mitchell TG. Prevalence of clinical isolates of Cryptococcus gattii serotype $\mathrm{C}$ among patients with AIDS in Sub-Saharan Africa. J Infect Dis 2005; 192(5): 888-92.

5. Mwaba $P$, Mwansa J, Chintu C, et al. Clinical presentation, natural history, and cumulative death rates of 230 adults with primary cryptococcal meningitis in Zambian AIDS patients treated under local conditions. Postgraduate Medical Journal 2001; 77(914): 76973.

6. Rajasingham R, Smith RM, Park BJ, et al. Global burden of disease of HIV-associated cryptococcal meningitis: an updated analysis. Lancet Infect Dis 2017.

7. Beardsley J, Sorrell TC, Chen SCA. Central Nervous System Cryptococcal Infections in Non-HIV Infected Patients. Journal of fungi (Basel, Switzerland) 2019; 5(3): 71.

8. Carlson RD, Rolfes MA, Birkenkamp KE, et al. Predictors of neurocognitive outcomes on antiretroviral therapy after cryptococcal meningitis: a prospective cohort study. Metabolic brain disease 2014; 29(2): 269-79.

9. Liao $\mathrm{CH}, \mathrm{Chi} \mathrm{CY}$, Wang YJ, et al. Different presentations and outcomes between HIVinfected and HIV-uninfected patients with Cryptococcal meningitis. Journal of Microbiology, Immunology \& Infection 2012; 45(4): 296-304.

10. Tenforde MW, Mokomane M, Leeme T, et al. Advanced Human Immunodeficiency Virus Disease in Botswana Following Successful Antiretroviral Therapy Rollout: Incidence of and Temporal Trends in Cryptococcal Meningitis. Clin Infect Dis 2017; 65(5): 779-86.

11. Britz E, Perovic O, von Mollendorf C, et al. The Epidemiology of Meningitis among Adults in a South African Province with a High HIV Prevalence, 2009-2012. PLOS ONE 2016; 11(9): e0163036.

12. Osler M, Hilderbrand K, Goemaere E, et al. The Continuing Burden of Advanced HIV Disease Over 10 Years of Increasing Antiretroviral Therapy Coverage in South Africa. Clinical Infectious Diseases 2018; 66(suppl_2): S118-S25.

13. Rhein J, Hullsiek KH, Evans EE, et al. Detrimental Outcomes of Unmasking Cryptococcal Meningitis With Recent ART Initiation. Open forum infectious diseases 2018; 5(8): ofy122-ofy.

14. Molloy SF, Kanyama C, Heyderman RS, et al. Antifungal Combinations for Treatment of Cryptococcal Meningitis in Africa. N Engl J Med 2018; 378(11): 1004-17.

15. The World Bank. World Bank Open Data. 2020. data.worldbank.org (accessed 13 March 2020). 
16. Butler EK, Boulware DR, Bohjanen PR, Meya DB. Long term 5-year survival of persons with cryptococcal meningitis or asymptomatic subclinical antigenemia in Uganda. PloS one 2012; 7(12).

17. Gaskell KM, Rothe C, Gnanadurai R, et al. A prospective study of mortality from cryptococcal meningitis following treatment induction with $1200 \mathrm{mg}$ oral fluconazole in Blantyre, Malawi. PLoS One 2014; 9(11): e110285.

18. Lessells RJ, Mutevedzi PC, Heller T, Newell ML. Poor long-term outcomes for cryptococcal meningitis in rural South Africa. S Afr Med J 2011; 101(4): 251-2.

19. Baldassarre R, Mdodo R, Omonge $E$, et al. Mortality after clinical management of AIDS-associated cryptococcal meningitis in Kenya. East African medical journal 2014; 91(5): 145-51.

20. Rothe C, Sloan DJ, Goodson P, et al. A prospective longitudinal study of the clinical outcomes from cryptococcal meningitis following treatment induction with $800 \mathrm{mg}$ oral fluconazole in Blantyre, Malawi. PLoS One 2013; 8(6): e67311.

21. Kendi C, Penner J, Koech J, et al. Predictors of outcome in routine care for Cryptococcal meningitis in Western Kenya: lessons for HIV outpatient care in resourcelimited settings. Postgrad Med J 2013; 89(1048): 73-7.

22. Lindenberg ADSC, Chang MR, Paniago AMM, et al. Clinical and epidemiological features of 123 cases of cryptococcosis in Mato Grosso do Sul, Brazil. Revista do Instituto de Medicina Tropical de São Paulo 2008; 50: 75-8.

23. Pyrgos V, Seitz AE, Steiner CA, Prevots DR, Williamson PR. Epidemiology of cryptococcal meningitis in the US: 1997-2009. PLoS One 2013; 8(2): e56269.

24. Lortholary $\mathrm{O}$, Poizat $\mathrm{G}$, Zeller V, et al. Long-term outcome of AIDS-associated cryptococcosis in the era of combination antiretroviral therapy. Aids 2006; 20(17): 2183-91. 25. Leeme T, Patel R, Azzo C. Mortality due to HIV-associated cryptococcal meningitis in Botswana in the ART era. Conference on Retroviruses and Opportunistic Infections (CROI), Seattle, WA; 2017; 2017.

26. Vidal JE, Gerhardt J, Peixoto de Miranda EJ, et al. Role of quantitative CSF microscopy to predict culture status and outcome in HIV-associated cryptococcal meningitis in a Brazilian cohort. Diagnostic Microbiology \& Infectious Disease 2012; 73(1): 68-73.

27. Mora DJ, da Cunha Colombo ER, Ferreira-Paim K, Andrade-Silva LE, Nascentes GAN, Silva-Vergara ML. Clinical, epidemiological and outcome features of patients with cryptococcosis in Uberaba, Minas Gerais, Brazil. Mycopathologia 2012; 173(5-6): 321-7.

28. Dammert $P$, Bustamante $B$, Ticona $E$, et al. Treatment of cryptococcal meningitis in Peruvian AIDS patients using amphotericin B and fluconazole. Journal of Infection 2008; 57(3): 260-5.

29. Jarvis JN, Lawn SD, Vogt M, Bangani N, Wood R, Harrison TS. Screening for cryptococcal antigenemia in patients accessing an antiretroviral treatment program in South Africa. Clin Infect Dis 2009; 48(7): 856-62.

30. Ganiem AR, Indrati AR, Wisaksana $R$, et al. Asymptomatic cryptococcal antigenemia is associated with mortality among HIV-positive patients in Indonesia. J Int AIDS Soc 2014; 17: 18821.

31. Mfinanga S, Chanda D, Kivuyo SL, et al. Cryptococcal meningitis screening and community-based early adherence support in people with advanced HIV infection starting antiretroviral therapy in Tanzania and Zambia: an open-label, randomised controlled trial. Lancet 2015; 385(9983): 2173-82. 
32. Ramachandran A, Manabe Y, Rajasingham R, Shah M. Cost-effectiveness of CRAGLFA screening for cryptococcal meningitis among people living with HIV in Uganda. BMC infectious diseases 2017; 17(1): 225-.

33. Johnson KT, Churchyard GJ, Sohn H, Dowdy DW. Cost-effectiveness of Preventive Therapy for Tuberculosis With Isoniazid and Rifapentine Versus Isoniazid Alone in HighBurden Settings. Clinical Infectious Diseases 2018; 67(7): 1072-8.

34. World Health Organization. Guidelines for the diagnosis, prevention, and management of cryptococcal disease in HIV-infected adults, adolescents and children. Geneva: World Health Organization, 2018.

35. Hoving JC, Brown GD, Gómez BL, et al. AIDS-Related Mycoses: Updated Progress and Future Priorities. Trends Microbiol 2020; 28(6): 425-8.

36. Meya DB, Kiragga AN, Nalintya E, et al. Reflexive laboratory-based cryptococcal antigen screening and preemptive fluconazole therapy for cryptococcal antigenemia in HIVinfected individuals with $\mathrm{CD} 4<100$ cells/ $\mu \mathrm{L}$ : a stepped-wedge, cluster-randomized trial. Journal of acquired immune deficiency syndromes (1999) 2019; 80(2): 182.

37. Wake RM, Govender NP, Omar T, et al. Cryptococcal-related Mortality Despite Fluconazole Preemptive Treatment in a Cryptococcal Antigen Screen-and-Treat Program. Clin Infect Dis 2020; 70(8): 1683-90.

38. Jarvis JN, Tenforde MW, Lechiile K, et al. Evaluation of a Novel Semiquantitative Cryptococcal Antigen Lateral Flow Assay in Patients with Advanced HIV Disease. Journal of Clinical Microbiology 2020; 58(9): e00441-20.

39. Jarvis JN, Bicanic T, Loyse A, et al. Determinants of mortality in a combined cohort of 501 patients with HIV-associated Cryptococcal meningitis: implications for improving outcomes. Clin Infect Dis 2014; 58(5): 736-45.

40. Pastick KA, Bangdiwala AS, Abassi M, et al. Seizures in Human Immunodeficiency Virus-Associated Cryptococcal Meningitis: Predictors and Outcomes. Open Forum Infectious Diseases 2019; 6(11).

41. Brizendine KD, Baddley JW, Pappas PG. Predictors of mortality and differences in clinical features among patients with Cryptococcosis according to immune status. PLoS One 2013; 8(3): e60431.

42. Klock C, Cerski M, Goldani LZ. Histopathological aspects of neurocryptococcosis in HIV-infected patients: autopsy report of 45 patients. Int J Surg Pathol 2009; 17(6): 444-8. 43. Lee SC, Dickson DW, Casadevall A. Pathology of cryptococcal meningoencephalitis: analysis of 27 patients with pathogenetic implications. Hum Pathol 1996; 27(8): 839-47. 44. McMullan BJ, Sorrell TC, Chen SC-A. Cryptococcus gattii infections: contemporary aspects of epidemiology, clinical manifestations and management of infection. Future microbiology 2013; 8(12): 1613-31.

45. Robertson EJ, Najjuka G, Rolfes MA, et al. Cryptococcus neoformans ex vivo capsule size is associated with intracranial pressure and host immune response in HIV-associated cryptococcal meningitis. J Infect Dis 2014; 209(1): 74-82.

46. Rolfes MA, Hullsiek KH, Rhein J, et al. The effect of therapeutic lumbar punctures on acute mortality from cryptococcal meningitis. Clin Infect Dis 2014; 59(11): 1607-14.

47. Bicanic T, Brouwer AE, Meintjes G, et al. Relationship of cerebrospinal fluid pressure, fungal burden and outcome in patients with cryptococcal meningitis undergoing serial lumbar punctures. AIDS 2009; 23(6): 701-6. 
48. Bicanic T, Muzoora C, Brouwer AE, et al. Independent association between rate of clearance of infection and clinical outcome of HIV-associated cryptococcal meningitis: analysis of a combined cohort of 262 patients. Clin Infect Dis 2009; 49(5): 702-9.

49. Meda J, Kalluvya S, Downs JA, et al. Cryptococcal Meningitis Management in Tanzania With Strict Schedule of Serial Lumber Punctures Using Intravenous Tubing Sets: An Operational Research Study. JAIDS Journal of Acquired Immune Deficiency Syndromes 2014; 66(2).

50. Boyles TH, Gatley E, Wasserman S, Meintjes G. Brief Report: Flow Rate of Cerebrospinal Fluid Through a Spinal Needle Can Accurately Predict Intracranial Pressure in Cryptococcal Meningitis. JAIDS Journal of Acquired Immune Deficiency Syndromes 2017; 74(3).

51. Bicanic $T$, Brouwer AE, Meintjes $G$, et al. Relationship of cerebrospinal fluid pressure, fungal burden and outcome in patients with cryptococcal meningitis undergoing serial lumbar punctures. AIDS 2009; 23(6): 701-6.

52. Beardsley J, Wolbers M, Kibengo FM, et al. Adjunctive Dexamethasone in HIVAssociated Cryptococcal Meningitis. New England Journal of Medicine 2016; 374(6): 542-54. 53. Day JN, Chau TT, Wolbers $M$, et al. Combination antifungal therapy for cryptococcal meningitis. N Engl J Med 2013; 368(14): 1291-302.

54. Pullen MF, Hullsiek KH, Rhein J, et al. CSF early fungicidal activity as a surrogate endpoint for cryptococcal meningitis survival in clinical trials. Clin Infect Dis 2020.

55. Molefi M, Chofle AA, Molloy SF, et al. AMBITION-cm: intermittent high dose AmBisome on a high dose fluconazole backbone for cryptococcal meningitis induction therapy in sub-Saharan Africa: study protocol for a randomized controlled trial. Trials 2015; 16: 276.

56. Larsen RA, Bozzette SA, Jones BE, et al. Fluconazole combined with flucytosine for treatment of cryptococcal meningitis in patients with AIDS. Clin Infect Dis 1994; 19(4): 7415.

57. Kanyama C, Molloy SF, Chan AK, et al. One-year Mortality Outcomes From the Advancing Cryptococcal Meningitis Treatment for Africa Trial of Cryptococcal Meningitis Treatment in Malawi. Clinical Infectious Diseases 2019; 70(3): 521-4.

58. Lawrence DS, Youssouf N, Molloy SLF, et al. AMBIsome Therapy Induction OptimisatioN (AMBITION): High Dose AmBisome for Cryptococcal Meningitis Induction Therapy in sub-Saharan Africa: Study Protocol for a Phase 3 Randomised Controlled NonInferiority Trial. Trials 2018; 19(1): 649.

59. Stott KE, Hope W. Pharmacokinetics-pharmacodynamics of antifungal agents in the central nervous system. Expert Opinion on Drug Metabolism \& Toxicology 2018; 14(8): 80315.

60. Ernst EJ, Klepser ME, Pfaller MA. Postantifungal effects of echinocandin, azole, and polyene antifungal agents against Candida albicans and Cryptococcus neoformans.

Antimicrobial agents and chemotherapy 2000; 44(4): 1108-11.

61. Schwarz P, Dromer F, Lortholary O, Dannaoui E. Efficacy of amphotericin B in combination with flucytosine against flucytosine-susceptible or flucytosine-resistant isolates of Cryptococcus neoformans during disseminated murine cryptococcosis. Antimicrob Agents Chemother 2006; 50(1): 113-20.

62. Nussbaum JC, Jackson A, Namarika D, et al. Combination flucytosine and high-dose fluconazole compared with fluconazole monotherapy for the treatment of cryptococcal meningitis: a randomized trial in Malawi. Clin Infect Dis 2010; 50(3): 338-44. 
63. Saag MS, Powderly WG, Cloud GA, et al. Comparison of amphotericin B with fluconazole in the treatment of acute AIDS-associated cryptococcal meningitis. The NIAID Mycoses Study Group and the AIDS Clinical Trials Group. N Engl J Med 1992; 326(2): 83-9. 64. Mayanja-Kizza H, Oishi K, Mitarai S, et al. Combination therapy with fluconazole and flucytosine for cryptococcal meningitis in Ugandan patients with AIDS. Clin Infect Dis 1998; 26(6): 1362-6.

65. Bicanic T, Meintjes G, Wood R, et al. Fungal Burden, Early Fungicidal Activity, and Outcome in Cryptococcal Meningitis in Antiretroviral-Naive or Antiretroviral-Experienced Patients Treated with Amphotericin B or Fluconazole. Clinical Infectious Diseases 2007; 45(1): 76-80.

66. Stone NR, Rhodes J, Fisher MC, et al. Dynamic ploidy changes drive fluconazole resistance in human cryptococcal meningitis. The Journal of clinical investigation 2019; 129(3).

67. Stott KE, Beardsley J, Kolamunnage-Dona R, et al. Population Pharmacokinetics and Cerebrospinal Fluid Penetration of Fluconazole in Adults with Cryptococcal Meningitis. Antimicrob Agents Chemother 2018; 62(9).

68. Kneale M, Bartholomew JS, Davies E, Denning DW. Global access to antifungal therapy and its variable cost. Journal of Antimicrobial Chemotherapy 2016; 71(12): 3599606.

69. Shroufi A, Govender NP, Meintjes G, et al. Time to embrace access programmes for medicines: Lessons from the South African flucytosine access programme. International Journal of Infectious Diseases 2020.

70. Loyse A, Burry J, Cohn J, et al. Leave no one behind: response to new evidence and guidelines for the management of cryptococcal meningitis in low-income and middleincome countries. Lancet Infect Dis 2019; 19(4): e143-e7.

71. Merry M, Boulware DR. Cryptococcal Meningitis Treatment Strategies Affected by the Explosive Cost of Flucytosine in the United States: A Cost-effectiveness Analysis. Clin Infect Dis 2016; 62(12): 1564-8.

72. Jarvis JN, Harrison TS. Reply to Rajasingham and Boulware. Clin Infect Dis 2019; 69(4): 732-5.

73. Shiri T, Loyse A, Mwenge L, et al. Addition of Flucytosine to Fluconazole for the Treatment of Cryptococcal Meningitis in Africa: A Multicountry Cost-effectiveness Analysis. Clinical Infectious Diseases 2019; 70(1): 26-9.

74. Mylan. Global Social Responsibility 2018 Progress Report.: Mylan, 2019.

75. Ramamurthy M. Strides receives FDA approval for Flucytosine Capsules. Product approval from flagship facility in Bangalore to be marketed by Strides Pharma Inc in the US market. Bangalore: Strides Pharma Science Limited; 2020.

76. UNITAID. Unitaid invests to cut HIV-related deaths. 2020. https://unitaid.org/advanced-hiv-disease/\#en (accessed 20 April 2020).

77. Chen T, Mwenge L, Lakhi S, et al. Healthcare Costs and Life-years Gained From Treatments Within the Advancing Cryptococcal Meningitis Treatment for Africa (ACTA) Trial on Cryptococcal Meningitis: A Comparison of Antifungal Induction Strategies in Sub-Saharan Africa. Clinical Infectious Diseases 2019; 69(4): 588-95.

78. World Health Organization. Model List of Essential Medicines, 21st List, 2019. Geneva; 2019.

79. Gilead Sciences. Gilead Sciences Announces Steep Discounts for Ambisome to Treat Cryptococcal Meningitis in Low- and Middle-Income Countries. 2018. 
https://www.gilead.com/news-and-press/company-statements/discount-for-ambisome (accessed 27 February 2020).

80. Antiretroviral Procurement Working Group. ARV Procurement Working Group. 2020. https://www.arvprocurementworkinggroup.org/?l=en (accessed 26 May 2020).

81. Bicanic T, Bottomley C, Loyse A, et al. Toxicity of amphotericin B deoxycholate-based induction therapy in patients with HIV-associated cryptococcal meningitis. Antimicrobial agents and chemotherapy 2015; 59(12): 7224-31.

82. Bahr NC, Rolfes MA, Musubire A, et al. Standardized electrolyte supplementation and fluid management improves survival during amphotericin therapy for cryptococcal meningitis in resource-limited settings. Open Forum Infect Dis 2014; 1(2): ofu070.

83. Stott KE, Beardsley J, Whalley S, et al. Amphotericin B Deoxycholate in adults with Cryptococcal Meningitis; a Population Pharmacokinetic Model and Meta-Analysis of Outcomes. Antimicrob Agents Chemother 2018.

84. Bicanic T, Wood R, Meintjes G, et al. High-dose amphotericin B with flucytosine for the treatment of cryptococcal meningitis in HIV-infected patients: a randomized trial. Clin Infect Dis 2008; 47(1): 123-30.

85. Vermes A, van der Sijs H, Guchelaar HJ. Flucytosine: Correlation between Toxicity and Pharmacokinetic Parameters. Chemotherapy 2000; 46(2): 86-94.

86. Panomvana Na Ayudhya D, Thanompuangseree N, Tansuphaswadikul S. Effect of rifampicin on the pharmacokinetics of fluconazole in patients with AIDS. Clin Pharmacokinet 2004; 43(11): 725-32.

87. Kasibante J, Rutakingirwa MK, Kagimu E, et al. Tuberculosis preventive therapy (TPT) to prevent tuberculosis co-infection among adults with HIV-associated cryptococcal meningitis: A clinician's perspective. Journal of Clinical Tuberculosis and Other Mycobacterial Diseases 2020; 20: 100180.

88. Casadevall A, Pirofski LA. Host-pathogen interactions: redefining the basic concepts of virulence and pathogenicity. Infect Immun 1999; 67(8): 3703-13.

89. Pirofski L-a, Casadevall A. The Damage-Response Framework as a Tool for the Physician-Scientist to Understand the Pathogenesis of Infectious Diseases. The Journal of Infectious Diseases 2018; 218(suppl_1): S7-S11.

90. Scriven JE, Graham LM, Schutz C, et al. A Glucuronoxylomannan-Associated Immune Signature, Characterized by Monocyte Deactivation and an Increased Interleukin 10 Level, Is a Predictor of Death in Cryptococcal Meningitis. J Infect Dis 2016; 213(11): 1725-34.

91. Jarvis JN, Meintjes G, Bicanic T, et al. Cerebrospinal fluid cytokine profiles predict risk of early mortality and immune reconstitution inflammatory syndrome in HIV-associated cryptococcal meningitis. PLoS Pathog 2015; 11(4): e1004754.

92. Siddiqui $\mathrm{AA}$, Brouwer $\mathrm{AE}$, Wuthiekanun $\mathrm{V}$, et al. IFN-gamma at the site of infection determines rate of clearance of infection in cryptococcal meningitis. J Immunol 2005; 174(3): 1746-50.

93. Jarvis JN, Meintjes $\mathrm{G}$, Rebe K, et al. Adjunctive interferon-gamma immunotherapy for the treatment of HIV-associated cryptococcal meningitis: a randomized controlled trial. Aids 2012; 26(9): 1105-13.

94. Panackal AA, Wuest SC, Lin YC, et al. Paradoxical Immune Responses in Non-HIV Cryptococcal Meningitis. PLoS Pathog 2015; 11(5): e1004884.

95. Pappas PG, Bustamante B, Ticona $E$, et al. Recombinant interferon-gamma $1 \mathrm{~b}$ as adjunctive therapy for AIDS-related acute cryptococcal meningitis. J Infect Dis 2004;

189(12): 2185-91. 
96. Jarvis JN, Casazza JP, Stone HH, et al. The phenotype of the Cryptococcus-specific CD4+ memory T-cell response is associated with disease severity and outcome in HIVassociated cryptococcal meningitis. J Infect Dis 2013; 207(12): 1817-28.

97. Larsen RA, Pappas PG, Perfect J, et al. Phase I evaluation of the safety and pharmacokinetics of murine-derived anticryptococcal antibody $18 \mathrm{~B} 7$ in subjects with treated cryptococcal meningitis. Antimicrob Agents Chemother 2005; 49(3): 952-8.

98. Maciel RA, Ferreira LS, Wirth F, et al. Corticosteroids for the management of severe intracranial hypertension in meningoencephalitis caused by Cryptococcus gattii: A case report and review. J Mycol Med 2017; 27(1): 109-12.

99. Mehta GU, Panackal AA, Murayi R, Bennett JE, Williamson PR, Chittiboina P. Corticosteroids for shunted previously healthy patients with non-HIV cryptococcal meningoencephalitis. J Neurol Neurosurg Psychiatry 2018; 89(2): 219-20.

100. Phillips $\mathrm{P}$, Chapman K, Sharp M, et al. Dexamethasone in Cryptococcus gattii central nervous system infection. Clinical Infectious Diseases 2009; 49(4): 591-5.

101. Beardsley J, Hoang NLT, Kibengo FM, et al. Do intra-cerebral cytokine responses explain the harmful effects of dexamethasone in HIV-associated cryptococcal meningitis? Clinical Infectious Diseases 2018: ciy725-ciy.

102. Müller M, Wandel S, Colebunders R, Attia S, Furrer H, Egger M. Immune reconstitution inflammatory syndrome in patients starting antiretroviral therapy for HIV infection: a systematic review and meta-analysis. The Lancet infectious diseases 2010; 10(4): 251-61.

103. Boulware DR, Meya DB, Bergemann TL, et al. Clinical features and serum biomarkers in HIV immune reconstitution inflammatory syndrome after cryptococcal meningitis: a prospective cohort study. PLoS Med 2010; 7(12): e1000384.

104. Bicanic T, Meintjes G, Rebe K, et al. Immune Reconstitution Inflammatory Syndrome in HIV-Associated Cryptococcal Meningitis: A Prospective Study. JAIDS Journal of Acquired Immune Deficiency Syndromes 2009; 51(2).

105. Sun HY, Alexander BD, Huprikar S, et al. Predictors of immune reconstitution syndrome in organ transplant recipients with cryptococcosis: implications for the management of immunosuppression. Clin Infect Dis 2015; 60(1): 36-44.

106. Perfect JR, Dismukes WE, Dromer F, et al. Clinical practice guidelines for the management of cryptococcal disease: 2010 update by the infectious diseases society of america. Clin Infect Dis 2010; 50(3): 291-322.

107. Baddley JW, Forrest GN, Practice AIDCo. Cryptococcosis in solid organ transplantation-guidelines from the American Society of Transplantation Infectious Diseases Community of Practice. Clinical transplantation 2019; 33(9): e13543.

108. Williamson PR. Post-infectious inflammatory response syndrome (PIIRS): Dissociation of T-cell-macrophage signaling in previously healthy individuals with cryptococcal fungal meningoencephalitis. Macrophage 2015; 2: e1078.

109. Boulware DR, Bonham SC, Meya DB, et al. Paucity of initial cerebrospinal fluid inflammation in cryptococcal meningitis is associated with subsequent immune reconstitution inflammatory syndrome. J Infect Dis 2010; 202(6): 962-70.

110. Stone SF, Price P, Keane NM, Murray RJ, French MA. Levels of IL-6 and soluble IL-6 receptor are increased in HIV patients with a history of immune restoration disease after HAART. HIV Med 2002; 3(1): 21-7. 
111. Chang CC, Dorasamy AA, Gosnell BI, et al. Clinical and mycological predictors of cryptococcosis-associated immune reconstitution inflammatory syndrome. Aids 2013; 27(13): 2089-99.

112. Jarvis JN, Meintjes G, Bicanic T, et al. Cerebrospinal fluid cytokine profiles predict risk of early mortality and immune reconstitution inflammatory syndrome in HIV-associated cryptococcal meningitis. PLoS Pathogens 2015; 11(4): e1004754.

113. Chang CC, Omarjee S, Lim A, et al. Chemokine levels and chemokine receptor expression in the blood and the cerebrospinal fluid of HIV-infected patients with cryptococcal meningitis and cryptococcosis-associated immune reconstitution inflammatory syndrome. J Infect Dis 2013; 208(10): 1604-12.

114. Wiesner DL, Boulware DR. Cryptococcus-Related Immune Reconstitution Inflammatory Syndrome(IRIS): Pathogenesis and Its Clinical Implications. Current fungal infection reports $2011 ;$ 5(4): 252-61.

115. Scriven JE, Rhein J, Hullsiek KH, et al. Early ART After Cryptococcal Meningitis Is Associated With Cerebrospinal Fluid Pleocytosis and Macrophage Activation in a Multisite Randomized Trial. The Journal of infectious diseases 2015; 212(5): 769-78.

116. Alufandika M, Lawrence DS, Boyer-Chammard T, et al. A pragmatic approach to managing antiretroviral therapy-experienced patients diagnosed with HIV-associated cryptococcal meningitis: impact of antiretroviral therapy adherence and duration. AIDS 2020; 34(9).

117. Lortholary $\mathrm{O}$, Fontanet $\mathrm{A}$, Mémain $\mathrm{N}$, et al. Incidence and risk factors of immune reconstitution inflammatory syndrome complicating HIV-associated cryptococcosis in France. Aids 2005; 19(10): 1043-9.

118. Jarvis JN, Harrison TS. Understanding Causal Pathways in Cryptococcal Meningitis Immune Reconstitution Inflammatory Syndrome. The Journal of Infectious Diseases 2018; 219(3): 344-6.

119. World Health Organization. WHO case definitions of HIV for surveillance and revised clinical staging and immunological classification of HIV-related disease in adults and children. Geneva; 2007.

120. Hurtado JC, Castillo P, Fernandes F, et al. Mortality due to Cryptococcus neoformans and Cryptococcus gattii in low-income settings: an autopsy study. Scientific Reports 2019; 9(1): 7493.

121. Jarvis JN, Meintjes G, Williams A, Brown Y, Crede T, Harrison TS. Adult meningitis in a setting of high HIV and TB prevalence: findings from 4961 suspected cases. BMC Infectious Diseases 2010; 10(1): 67.

122. Mukolo A, Villegas R, Aliyu M, Wallston KA. Predictors of Late Presentation for HIV Diagnosis: A Literature Review and Suggested Way Forward. AIDS and Behavior 2013; 17(1): 5-30.

123. Vijayan T, Chiller T, Klausner JD. Sensitivity and specificity of a new cryptococcal antigen lateral flow assay in serum and cerebrospinal fluid. MLO: medical laboratory observer 2013; 45(3): 16-20.

124. Boulware DR, Rolfes MA, Rajasingham R, et al. Multisite validation of cryptococcal antigen lateral flow assay and quantification by laser thermal contrast. Emerging infectious diseases 2014; 20(1): 45.

125. World Health Organization. The Global Health Observatory. 2018. https://www.who.int/data/gho (accessed 29 May 2020). 
126. World Health Organization. Guidelines for managing advanced HIV disease and rapid initiation of antiretroviral therapy, July 2017. Geneva; 2017.

127. Elizabeth Glaser Pediatric AIDS Foundation. Global Advanced HIV Disease Toolkit. 2020. https://www.pedaids.org/resource/global-advanced-hiv-disease-toolkit/ (accessed 19 June 2020).

128. Rhein J, Huppler Hullsiek K, Tugume L, et al. Adjunctive sertraline for HIV-associated cryptococcal meningitis: a randomised, placebo-controlled, double-blind phase 3 trial. Lancet Infect Dis 2019; 19(8): 843-51.

129. Day J. Best Options in Cryptococcosis. European Conference on Clinical Microbiology and Infectious Diseases. Amsterdam; 2019.

130. Harper R. Fast Track designation granted to fosmanogepix for seven indications. 2019. https://www.europeanpharmaceuticalreview.com/news/99331/fast-trackdesignantion-granted-fosmanogepix/ (accessed 24 September 2019).

131. Hodges MR, Ople E, Shaw KJ, et al. First-in-Human Study to Assess Safety, Tolerability and Pharmacokinetics of APX001 Administered by Intravenous Infusion to Healthy Subjects. Open Forum Infectious Diseases 2017; 4(suppl_1): S526-S.

132. Lindsay J, Sandaradura I, Wong K, et al. Serum levels, safety and tolerability of new formulation SUBA-itraconazole prophylaxis in patients with haematological malignancy or undergoing allogeneic stem cell transplantation. J Antimicrob Chemother 2017; 72(12): 3414-9.

133. Rauseo AM, Coler-Reilly A, Larson L, Spec A. Hope on the Horizon: Novel Fungal Treatments in Development. Open Forum Infectious Diseases 2020; 7(2).

134. Mitsuyama J, Nomura N, Hashimoto K, et al. In Vitro and In Vivo Antifungal Activities of T-2307, a Novel Arylamidine. Antimicrobial Agents and Chemotherapy 2008; 52(4): 131824.

135. Appili Therapeutics. A Novel, Broad Spectrum, Clinical Stage Antifungal to Address Severe and Difficult-to-Treat Invasive Fungal Infections. 2020. https://www.appilitherapeutics.com/ati-2307 (accessed 26 August 2020).

136. Mateo J, De Bono JS, Ramanathan RK, et al. A first-in-human phase I trial of AR-12, a PDK-1 inhibitor, in patients with advanced solid tumors. Journal of Clinical Oncology 2013; 31(15_suppl): 2608-.

137. Lu R, Hollingsworth C, Qiu J, et al. Efficacy of Oral Encochleated Amphotericin B in a Mouse Model of Cryptococcal Meningoencephalitis. mBio 2019; 10(3): e00724-19.

138. Wiederhold NP, Xu X, Wang A, et al. In Vivo Efficacy of VT-1129 against Experimental Cryptococcal Meningitis with the Use of a Loading Dose-Maintenance Dose Administration Strategy. Antimicrobial Agents and Chemotherapy 2018; 62(11): e01315-18.

139. Shaw KJ, Schell WA, Covel J, et al. $\mathrm{n}$ Vitro and In Vivo Evaluation of APX001A/APX001 and Other Gwt1 Inhibitors against Cryptococcus. Antimicrobial Agents and Chemotherapy 2018; 62(8): e00523-18.

140. European and Developing Countries Clinical Trials Partnership. Advances in product development for effective prevention, treatment and management of co-infections and comorbidities - 2018. http://www.edctp.org/projects-2/edctp2-projects/advances-in-productdevelopment-for-effective-prevention-treatment-and-management-of-co-infections-andco-morbidities-2018/ (accessed 26 May 2020).

141. Smilnak GJ, Charalambous LT, Cutshaw D, et al. Novel Treatment of Cryptococcal Meningitis via Neurapheresis Therapy. J Infect Dis 2018; 218(7): 1147-54. 
142. Food and Drug Administration. Designating Additions to the Current List of Tropical Diseases in the Federal Food, Drug, and Cosmetic Act. 2018. p. 42904-10 (7 pages).

143. Molloy SF, Chiller T, Greene GS, et al. Cryptococcal meningitis: A neglected NTD? PLOS Neglected Tropical Diseases 2017; 11(6): e0005575.

144. Chapman N, Boubell A, Barnsley P, et al. Neglected disease research and development: Uneven progress: G-FINDER, 2019.

145. Oladele RO, Jordan A, Akande $P$, et al. Tackling cryptococcal meningitis in Nigeria, one-step at a time; the impact of training. PLOS ONE 2020; 15(7): e0235577.

146. Médicins Sans Frontières. MSF access calls on Gilead to urgently make its life-saving cryptococcal meningitis treatment more accessible and affordable. 2018.

https://msfaccess.org/msf-response-new-who-guidelines-hiv-related-cryptococcal-disease (accessed 27 February 2020).

147. Policy Cures Research. G-FINDER data portal.

https://gfinderdata.policycuresresearch.org (accessed 7 May 2020). 
Table 1: Potential drugs in development for cryptococcal meningoencephalitis

\begin{tabular}{|c|c|c|c|c|c|c|c|c|}
\hline $\begin{array}{c}\text { Drug/ } \\
\text { compound } \\
\text { (Developer) }\end{array}$ & $\begin{array}{c}\text { Phase of } \\
\text { development }\end{array}$ & $\begin{array}{c}\text { Mechanism of } \\
\text { action }\end{array}$ & Administration & $\begin{array}{l}\text { Clinical PK } \\
\text { profile }\end{array}$ & Potential utility for CME & $\begin{array}{c}\text { In vitro } \\
\text { efficacy } \\
\text { comparable } \\
\text { to or better } \\
\text { than AmB? }\end{array}$ & $\begin{array}{c}\text { Clinical } \\
\text { tolerability }\end{array}$ & Refs \\
\hline $\begin{array}{c}\text { APX001/ } \\
\text { fosmanogepix } \\
\text { (Amplyx) }\end{array}$ & Phase II. & $\begin{array}{l}\text { Inhibits fungal } \\
\text { wall transfer } \\
\text { protein, Gwt1. }\end{array}$ & IV/ oral & NA & $\begin{array}{c}\text { In combination with other antifungals; } \\
\text { demonstrates PD synergy with } \\
\text { fluconazole. }\end{array}$ & $\checkmark$ & $\begin{array}{l}\text { Well tolerated } \\
\text { in first-in- } \\
\text { human studies. }\end{array}$ & 130,131 \\
\hline $\begin{array}{l}\text { SUBA- } \\
\text { itraconazole } \\
\text { (Mayne } \\
\text { Pharma) }\end{array}$ & Phase II. & $\begin{array}{c}\text { Inhibits } \\
\text { ergosterol } \\
\text { synthesis in } \\
\text { cell } \\
\text { membrane. } \\
\text { (Itraconazole } \\
\text { has shown } \\
\text { inconsistent } \\
\text { outcomes in } \\
\text { CME and has } \\
\text { highly variable } \\
\text { PK.) }\end{array}$ & Oral & $\begin{array}{l}\text { Rapid } \\
\text { attainment } \\
\text { of } \\
\text { therapeutic } \\
\text { plasma } \\
\text { levels. } \\
\text { Modest PK } \\
\text { variability. }\end{array}$ & $\begin{array}{l}\text { Potential for maintenance therapy in } \\
\text { place of fluconazole. }\end{array}$ & & $\begin{array}{c}\text { Better tolerated } \\
\text { than } \\
\text { conventional } \\
\text { itraconazole; } \\
\text { mucositis and } \\
\text { hepatotoxicity } \\
\text { reported. }\end{array}$ & 132 \\
\hline $\begin{array}{l}\text { VL-2397 } \\
\text { (ASP2397) }\end{array}$ & $\begin{array}{c}\text { Early } \\
\text { termination of } \\
\text { phase II trial } \\
\text { for aspergillosis } \\
\text { - business } \\
\text { decision. }\end{array}$ & $\begin{array}{l}\text { Unknown } \\
\text { intracellular } \\
\text { target. }\end{array}$ & IV & $\begin{array}{l}\text { Non-linear } \\
\text { saturable } \\
\text { binding } \\
\text { kinetics. }\end{array}$ & In combination with other antifungals. & & $\begin{array}{l}\text { Well tolerated } \\
\text { up to } 1200 \mathrm{mg} \text {. }\end{array}$ & 133 \\
\hline
\end{tabular}




\begin{tabular}{|c|c|c|c|c|c|c|c|c|}
\hline $\begin{array}{l}\text { ATI-2307 } \\
\text { (Appili } \\
\text { Therapeutics) }\end{array}$ & $\begin{array}{c}\text { Phase I } \\
\text { complete; } \\
\text { phase II } \\
\text { planned for } \\
2022 .\end{array}$ & $\begin{array}{l}\text { Allylamine that } \\
\text { inhibits } \\
\text { mitochondrial } \\
\text { membrane } \\
\text { potential }\end{array}$ & Subcutaneous & NA & $\begin{array}{c}\text { Greater potency than standard of care } \\
\text { agents. }\end{array}$ & $\checkmark$ & $\begin{array}{l}\text { Well tolerated } \\
\text { at anticipated } \\
\text { therapeutic } \\
\text { dosages. }\end{array}$ & 134,135 \\
\hline $\begin{array}{c}\text { AR-12 } \\
\text { (Arno } \\
\text { Therapeutics) }\end{array}$ & Phase I. & $\begin{array}{c}\text { Celecoxib } \\
\text { derivative. } \\
\text { Inhibits fungal } \\
\text { acetyl-coA } \\
\text { synthetase. }\end{array}$ & Oral & $\begin{array}{c}\text { Highly } \\
\text { variable PK. }\end{array}$ & $\begin{array}{l}\text { In combination with other antifungals; } \\
\text { demonstrates PD synergy with } \\
\text { fluconazole. }\end{array}$ & & $\begin{array}{l}\text { Well tolerated } \\
\text { at } 800 \mathrm{mg} \text { BID. }\end{array}$ & 136 \\
\hline $\begin{array}{l}\text { Encochleated } \\
\text { amphotericin } \\
\text { B/ MAT2203 } \\
\text { (Matinas) }\end{array}$ & $\begin{array}{l}\text { Pre-clinical; } \\
\text { FDA have } \\
\text { granted QIDP } \\
\text { and Fast Track } \\
\text { designations. }\end{array}$ & $\begin{array}{c}\text { Binds to } \\
\text { ergosterol; } \\
\text { fungicidal via } \\
\text { pore } \\
\text { formation in } \\
\text { cell } \\
\text { membrane. }\end{array}$ & Oral & NA & $\begin{array}{l}\text { Potential oral alternative to current } \\
\text { AmB preparations. }\end{array}$ & $\checkmark$ & $\begin{array}{c}\text { Promises lower } \\
\text { renal toxicity } \\
\text { than IV } \\
\text { formulations of } \\
\text { AmB. Mitigates } \\
\text { challenges } \\
\text { associated with } \\
\text { IV } \\
\text { administration. }\end{array}$ & 137 \\
\hline $\begin{array}{l}\text { VT-1129 } \\
\text { (Mycovia) }\end{array}$ & $\begin{array}{l}\text { Pre-clinical; } \\
\text { FDA have } \\
\text { granted QIDP } \\
\text { and Fast Track } \\
\text { designations. } \\
\text { Investigational } \\
\text { New Product } \\
\text { application } \\
\text { filed with FDA. }\end{array}$ & $\begin{array}{c}\text { Tetrazole: } \\
\text { Inhibits } \\
\text { ergosterol } \\
\text { synthesis in } \\
\text { cell membrane } \\
\text { by selectively } \\
\text { targeting } \\
\text { CYP51. }\end{array}$ & Oral & NA & $\begin{array}{l}\text { Potential low-cost agent for fluconazole- } \\
\text { resistant strains of Cryptococcus. }\end{array}$ & & NA & 138 \\
\hline $\begin{array}{l}\text { APX2096 } \\
\text { (Amplyx) }\end{array}$ & Pre-clinical. & $\begin{array}{l}\text { Gwt1 inhibitor } \\
\text { prodrug; } \\
\text { inhibits fungal } \\
\text { wall transfer } \\
\text { protein. }\end{array}$ & $\begin{array}{c}\text { Oral/ } \\
\text { intraperitoneal }\end{array}$ & NA & $\begin{array}{l}\text { 32-fold lower MIC against } C \text {. } \\
\text { neoformans compared with APX001. } \\
\text { Good CNS penetration. Demonstrates } \\
\text { PD synergy with fluconazole. }\end{array}$ & $\checkmark$ & NA & 139 \\
\hline $\begin{array}{l}\text { Aureobasidin } \\
\text { A (AureoGen }\end{array}$ & $\begin{array}{c}\text { Preclinical. } \\
\text { Discovered } \\
1989 \text { - license }\end{array}$ & $\begin{array}{l}\text { Inhibits } \\
\text { sphingolipid } \\
\text { synthesis in }\end{array}$ & $\begin{array}{c}\text { Oral/ } \\
\text { subcutaneous }\end{array}$ & NA & Potent anticryptococcal activity in vitro. & & NA & 133 \\
\hline
\end{tabular}




\begin{tabular}{|c|c|c|c|l|l|l|}
\hline Biosciences/ & $\begin{array}{c}\text { patent granted } \\
\text { in } 2007 \text { for } \\
\text { further } \\
\text { development. }\end{array}$ & $\begin{array}{c}\text { cell } \\
\text { membrane. }\end{array}$ & & & & \\
\hline
\end{tabular}

CME: Cryptococcal meningoencephalitis; PK: pharmacokinetic; AmB: amphotericin B; BID: bis in die (twice per day); IV: intravenous; FDA: Food and Drug Administration. QIDP: Qualified Infectious Disease Product. 
Table 2 Priority targets to reduce mortality from cryptococcal meningoencephalitis

\begin{tabular}{|c|c|}
\hline Priority area & Specific targets \\
\hline \multirow[t]{2}{*}{ CrAg screening } & $\begin{array}{l}\text { Screening must be rolled out across LMICs as part of packages of care } \\
\text { for AHD. }\end{array}$ \\
\hline & $\begin{array}{l}\text { Improved pre-emptive treatment options for patients who test } \mathrm{CrAg} \\
\text { positive are urgently required. }\end{array}$ \\
\hline \multirow[t]{2}{*}{$\begin{array}{l}\text { Optimised } \\
\text { treatments }\end{array}$} & $\begin{array}{l}\text { Universal access to evidence-based optimised treatment regimens } \\
\text { must be guaranteed across LMICs. }\end{array}$ \\
\hline & $\begin{array}{l}\text { Access must be supported by clinical and laboratory capacity to } \\
\text { mitigate, detect and manage adverse events. }\end{array}$ \\
\hline \multirow[t]{2}{*}{$\begin{array}{l}\text { Health system } \\
\text { strengthening }\end{array}$} & $\begin{array}{l}\text { Pragmatic interventions such as packages of care for AHD must be } \\
\text { supported by training, staffing and clinical and laboratory resources. }\end{array}$ \\
\hline & $\begin{array}{l}\text { Basic clinical equipment such as manometers and/or sterile LP kits } \\
\text { must be provided in LMICs. }\end{array}$ \\
\hline \multirow[t]{3}{*}{$\begin{array}{l}\text { Therapeutics } \\
\text { research }\end{array}$} & $\begin{array}{l}\text { The pharmacokinetics and pharmacodynamics of existing and novel } \\
\text { anti-cryptococcal drugs must be described. }\end{array}$ \\
\hline & Clinical trials to optimise pre-emptive therapy are urgently needed. \\
\hline & $\begin{array}{l}\text { The potential for manipulation of the host immune response as a } \\
\text { treatment strategy must be understood. }\end{array}$ \\
\hline Novel agents & Research and development of novel drugs remains an urgent priority. \\
\hline $\begin{array}{l}\text { Implementation } \\
\text { science }\end{array}$ & $\begin{array}{l}\text { In all areas, context-specific implementation science research to } \\
\text { identify barriers to roll-out of existing evidence based strategies is } \\
\text { essential to foster progress and capitalise on potential mortality } \\
\text { benefit. For example, implementation of universal CrAg screening and } \\
\text { qualitative research to explore patient and clinician barriers to } \\
\text { repeated LPs. }\end{array}$ \\
\hline
\end{tabular}

LMICs: Low- and middle-income countries; AHD: advanced HIV disease; CrAg: cryptococcal antigen 
Figure 1: ART coverage is not sufficient to reduce mortality from cryptococcal meningoencephalitis in resource-limited settings
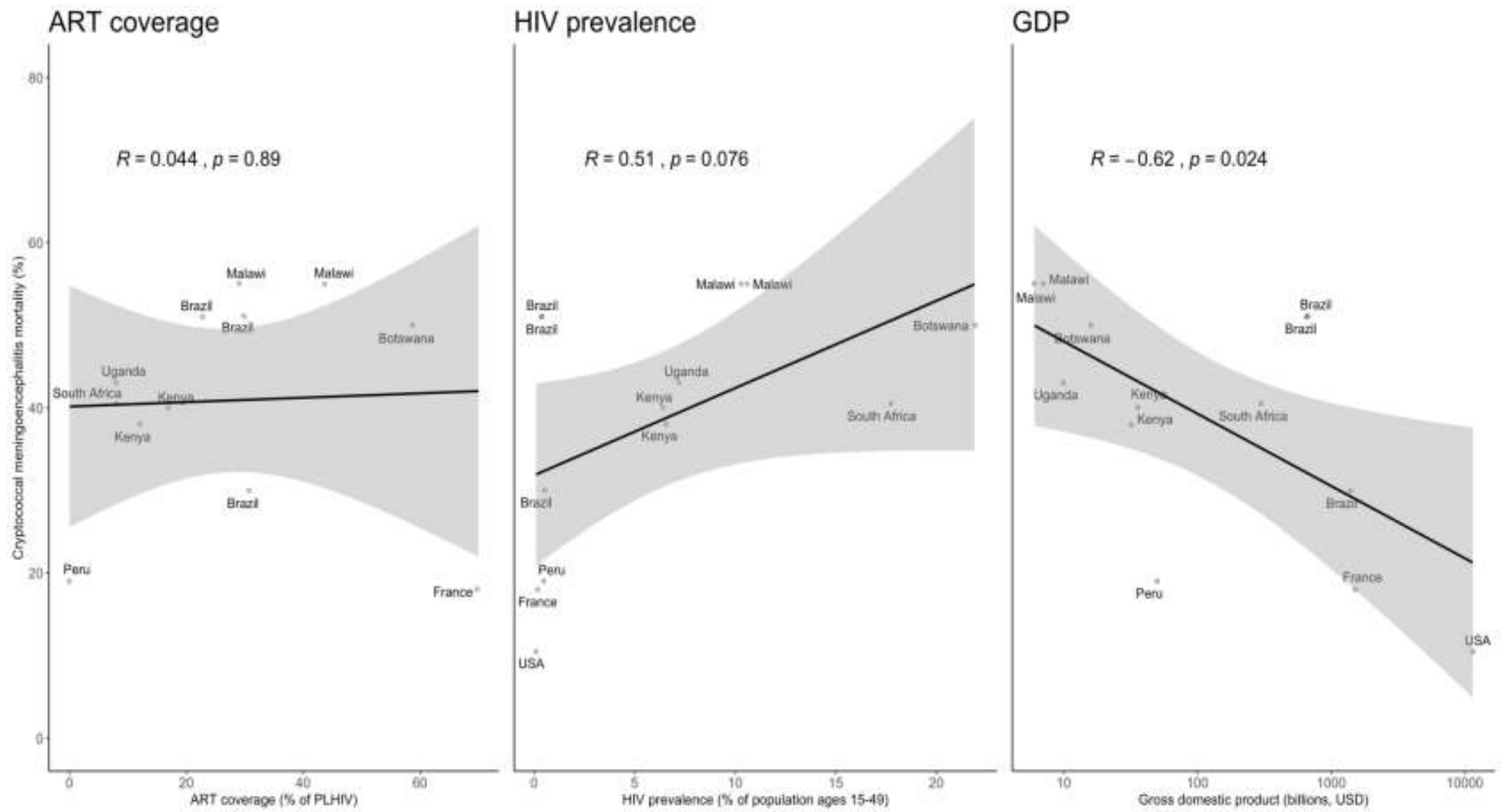

Cryptococcal meningoencephalitis mortality reported from observational studies. GDP, ART coverage and HIV prevalence reported from time of data collection. Data from ${ }^{15-28}$. ART: antiretroviral therapy. GDP: Gross domestic product. While there is no association between ART coverage and \% mortality from cryptococcal meningoencephalitis, there is a trend towards higher mortality with increased HIV prevalence, and a significant negative association between GDP and mortality. Mortality from cryptococcal meningoencephalitis results from a complex interplay of factors related to poverty, and ART coverage alone is insufficient to reduce it. 
Figure 2: Contributors to mortality from cryptococcal meningoencephalitis

\begin{tabular}{l} 
Overwhelmed Host \\
Immunosuppression \\
Polymicrobial infection \\
Malnutrition \\
Gastrointestinal disease and \\
malabsorption \\
Challenges with adherence \\
\hline
\end{tabular}

\section{Complex Pathology}

High CNS fungal burden

Raised ICP

Lack of early inflammation

Lack of classical macrophage

activation

IRIS

\section{System Failures}

Delays in diagnosis

Laboratory capacity

Staffing

Training

Clinical equipment

Risk of nosocomial infection

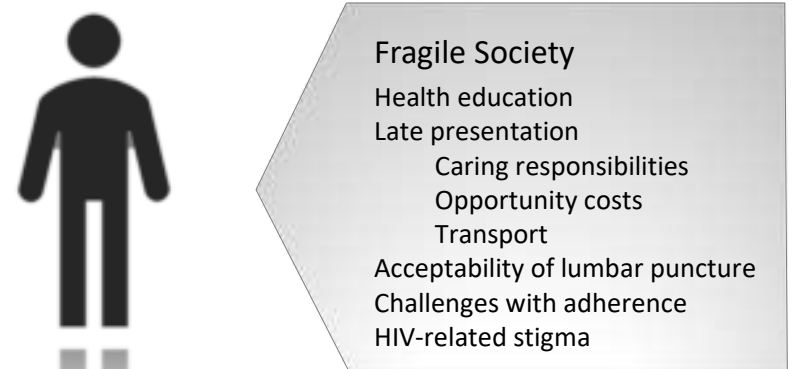

Research Gaps

Novel therapeutics

Optimised dosing of existing \&

novel drugs

Safe immunomodulation

Role of empirical therapeutic

lumbar puncture

CNS: Central nervous system; ICP: intracranial pressure; IRIS: immune reconstitution inflammatory syndrome 